\title{
Neuronal generators of posterior EEG alpha reflect individual differences in prioritizing personal spirituality
}

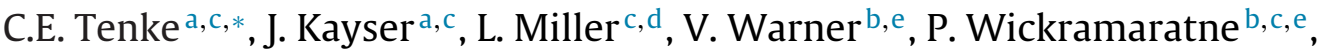 \\ M.M. Weissman ${ }^{\mathrm{b}, \mathrm{c}, \mathrm{e}}$, G.E. Bruder ${ }^{\mathrm{a}, \mathrm{c}}$ \\ a Division of Cognitive Neuroscience, NYS Psychiatric Institute, New York, NY, United States \\ b Division of Epidemiology, NYS Psychiatric Institute, New York, NY, United States \\ c Columbia University, College of Physicians and Surgeons, New York, NY, United States \\ d Columbia University, Teachers College, New York, NY, United States \\ e Columbia University, Mailman School of Public Health, New York, NY, United States
}

\section{A R T I C L E I N F O}

\section{Article history:}

Received 3 December 2012

Accepted 5 August 2013

Available online 30 August 2013

\section{Keywords:}

EEG alpha

Depression risk

Religion

Spirituality

Current source density

\begin{abstract}
A B S T R A C T
Prominent posterior EEG alpha is associated with depression and clinical response to antidepressants. Given that religious belief was protective against depression in a longitudinal study of familial risk, we hypothesized that individuals who differed by strength of spiritual beliefs might also differ in EEG alpha. Clinical evaluations and self-reports of the importance of religion or spirituality $(R / S)$ were obtained from 52 participants, and again at 10-y followup when EEG was measured. EEG alpha was quantified using frequency PCA of current source densities (CSD-fPCA). Participants who rated R/S as highly important at initial assessment showed greater alpha compared to those who did not. Those who rated R/S important in both sessions showed greater alpha than those who changed their ratings. EEG differences were particularly well-defined for participants with lifetime depression. Findings extend the view of alpha as a marker for affective processes, suggesting an association with the ontogenesis of spirituality.
\end{abstract}

(c) 2013 Elsevier B.V. All rights reserved.

\section{Introduction}

Since the time of Berger, EEG alpha has been identified as an idling rhythm characterizing relaxed wakefulness that is blocked (desynchronized) when visual processes are engaged by opening the eyes (Gloor, 1969). At an organismic scale, alpha blocking may be viewed as a form of alerting or arousal response. The inverse relationship between EEG alpha and activation is also consistent with physical relaxation or inattention to external stimuli. Notably, greater EEG alpha has been reported for experienced meditators compared to controls, a distinction attributed to both state-related changes and persistent (trait) differences between individuals (Cahn \& Polich, 2006). A similar functional conceptualization has been exploited in a series of studies using EEG alpha as an index of relative cortical deactivation (i.e., greater alpha, less activation), particularly in hemispheric asymmetry studies of depression (e.g., Allen \& Cohen, 2010; Bruder et al., 1997; Davidson, 1992; Henriques \& Davidson, 1990). These studies use EEG alpha as a functional measure, but the anatomical specificity

\footnotetext{
* Corresponding author at: Division of Cognitive Neuroscience, NYS Psychiatric Institute, 1051 Riverside Drive, New York, NY, United States. Tel.: +1 212543 5483; fax: +1 2125436540 .

E-mail address: cet2103@columbia.edu (C.E. Tenke).
}

of the measure may be insufficient to meaningfully localize effects to identifiable neuronal tissue, owing to the implications of volume conduction (Nunez \& Srinivasan, 2006; Tenke \& Kayser, 2012). In contrast, surface Laplacian methods offer sufficient regional and functional specificity to warrant comparisons with event-related potential components by exploiting the topographic properties of the EEG (e.g., Tenke \& Kayser, 2005; Tenke et al., 2011). Despite their early application to the resting EEG (cf. pp. 346-347 of Nunez \& Srinivasan, 2006), these reference-free methods have infrequently been applied to the study of depression (e.g., Allen \& Cohen, 2010; Kayser, Bruder, Tenke, Stewart, \& Quitkin, 2000; Stewart, Towers, Coan, \& Allen, 2011; Tenke \& Kayser, 2005; Tenke, Kayser, Stewart, \& Bruder, 2010; Tenke et al., 2011).

EEG alpha power has been associated with both the risk of, and prognosis for, major depression. Alpha power was elevated in euthymic adults who had recovered from depression (Pollock \& Schneider, 1989), prompting the suggestion that alpha power might identify individuals at risk for a depression due to family history of affective disorders (Pollock \& Schneider, 1990). ${ }^{1}$ We
${ }^{1}$ It should also be noted that other investigators have identified EEG theta as a predictor of antidepressant response (e.g., Knott et al., 1996; Korb et al., 2009; Mulert et al., 2007; Pizzagalli et al., 2001). Although the distinction between EEG theta and alpha activity is not always self-evident, owing to the possibility that broad spectral 
observed that offspring of two parents with MDD showed greater posterior, condition-dependent alpha (eyes-closed minus eyesopen during rest) compared to those with neither or only one depressed parent (Bruder et al., 2005), suggesting the transmission of a trait across generations. Bruder et al. (2008) reported that those who responded to treatment with to a selective serotonin reuptake inhibitor (SSRI) had greater alpha power compared with nonresponders and healthy control participants, the differences being greatest at posterior sites and persistent following treatment. Using a larger sample and stronger methods (dense recording montage, current source density [CSD] transformation, frequency principal components analysis [fPCA]), Tenke et al. (2011) identified prominent posterior alpha as predictive of a good antidepressant treatment response to a SSRI or dual therapy with a serotonergic plus nonserotonergic antidepressant. Similar differences have also been found between responders and nonresponders to a nonserotonergic antidepressant (Knott, Telner, Lapierre, Browne, \& Horn, 1996; Tenke et al., 2013; Ulrich, Haug, Stieglitz, \& Fähndrich, 1988). However, it is not yet known to what extent individuals who have positive outcomes following other treatments, or who have spontaneous remissions, might also show differences in posterior alpha.

Another line of evidence links depression risk with personal spirituality and religion. Personal importance of religion or spirituality $(R / S)$ has been reported to be protective against depression in multiple studies, and supported by a meta-analysis (Kendler, Gardner, \& Prescott, 1997; Smith, McCullough, \& Poll, 2003). One study observed that adult offspring of depressed probands (high familial risk) who indicated that $\mathrm{R} / \mathrm{S}$ was personally highly important to them had a markedly reduced risk of developing major depression (MDD) over the subsequent ten years compared to those who did not (Miller et al., 2012). Moreover, those who reported high personal importance of R/S showed greater cortical thickness (structural MRI) at a subsequent scan when compared to those who did not (Miller et al., 2013), and this difference involved the same cortical regions where thinning provides an endophenotype for depression (Peterson et al., 2009). Of particular relevance, cortical thinning may partially account for the enhancement of alpha in individuals at risk for MDD (Bruder et al., 2012).

These observations collectively suggest that depression and spirituality may share a common functional basis with direct implications for the activity patterns evidenced by posterior EEG alpha. When prospectively identified, the protective effects of personal spirituality against depressive symptomatology provide a behavioral predictor of a positive outcome for individuals at risk for depression over the following ten-year period (Miller et al., 2012). It was therefore hypothesized that those individuals predicted to have the greatest protection against depression by virtue of their personal spirituality would show greater posterior EEG alpha (quantified by CSD-fPCA) at the subsequent assessment.

Posterior EEG alpha patterns are trait-like, in that individual differences may persist following treatment or recovery from depression (e.g., Bruder et al., 2008; Pollock \& Schneider, 1990). Religious beliefs and practices may also persist over considerable periods of time, and tend to be transgenerational. Indeed, the concordance of maternal and offspring religiosity is itself associated with reduced risk for, and recovery from, depression (Miller, Warner, Wickramaratne, \& Weissman, 1997; Miller et al., 2012). However, the structural differences associated with personal importance of R/S were less robust for those who changed their valuation of importance over time (Miller et al., 2013). We therefore predicted that individuals who changed their valuation

peaks may be misidentified if they cross the a priori limits of frequency bands (cf. Tenke \& Kayser, 2005; Tenke et al., 2011), there is considerable evidence that the classically defined EEG alpha rhythm is related to depression.
Table 1

Lifetime MDD by familial risk.

\begin{tabular}{llcc}
\hline & No MDD & MDD & \\
\hline Low risk & 15 & 6 & 21 \\
High risk & 10 & 21 & 31 \\
& 25 & 27 & 52 \\
\hline
\end{tabular}

Fisher's exact test: $p=.006$

of personal spirituality over the ten-year period would show less posterior EEG alpha than those who maintained their importance of $\mathrm{R} / \mathrm{S}$ at followup.

\section{Methods}

\subsection{Participants}

Fifty-two adult participants (33 female) were part of a multiwave threegeneration longitudinal study of individuals at high and low risk for major depression based on family history (Weissman, Warner, Wickramaratne, Moreau, \& Olfson, 1997; Weissman et al., 2005, 2006) who had EEG recordings at year 20 of the study (T20; mean age $37 \mathrm{yrs} \pm 5.7$ ). In the original wave of the study, probands with moderate to severe major depressive disorder were selected from outpatient clinics for the psychopharmacologic treatment of mood disorders, and nondepressed, demographically-matched control participants were selected from an epidemiologic sample of adults with no psychiatric history from the same community. The sample was recruited from an urban setting (greater New Haven area, Connecticut, US), and consisted of Caucasian and working or middle class individuals. Clinical assessments were conducted by independent interviewers who were blind to the participant's previous clinical history (personal or family).

The assessments reported in this study were from waves at year 10 (T10; beginning 1992) and year 20 (T20; beginning 2002) of the study, and were approved by the institutional review boards at Yale University and at Columbia University/New York State Psychiatric Institute. All participants gave written informed consent. As indicated in Table 1, 31 participants were from the high risk group, which was characterized by significantly greater lifetime rates of MDD than the 21 participants in the low risk group (Fisher's exact test, one-sided, $p=.006$ ).

\subsection{Religiosity}

Included in the information collected were participant responses on the personal importance of religion at T10 and T20. The classifier question was "How important is religion or spirituality to you?," with response options ranging from 1 ("not important at all") to 4 ("highly important"). This item has been found to show robust correlations with the widely used Fetzer Institute full-scale measure of personal spirituality (Idler et al., 2003). The terms "religion" and "spirituality" were both included in this question because they are frequently linked together in studies on health (Koenig, McCullough, \& Larson, 2001; Larson \& Larson, 2003; Tsuang, Williams, Simpson, \& Lyons, 2002). Participant responses were dichotomized as "Highly Important" vs. all other responses on the basis of prior findings (Miller et al., 1997, 2012), and will hereafter be referred to as "Important" and "Not Important" for sake of brevity.

Table 2 shows the importance classification of all participants at T10 and T20 assessments, indicating subgroup classifications (italics) and corresponding cell sizes for the resulting subgroups and the cross-tabulation marginals (row and column sums). For the primary hypothesis (based on T10), 12 of the 52 participants were initially categorized as "Important." Four of these changed their prioritization when reassessed at T20 (i.e., they "Migrated Out" of their prioritization). However, the total number who prioritized R/S as Important at T20 increased to 20, including 12 initially classified as "Not Important" at T10 (i.e., they "Migrated In" to their prioritization). The remaining 28 were stable in their expression of faith as "Not Important" (i.e., "Never" prioritized as “Important").

Table 3 describes the composition of these subgroupings by familial risk, lifetime MDD, and gender, with major Importance headings shown for T10 (i.e., the primary hypothesis). Females were more likely than males to rate R/S as "Important" at either assessment (Always plus Migrate Out plus Migrate In; 19 out of 33 vs. 5 out of 19; Fisher exact test, two-sided, $p=.044)$. Lifetime history of MDD was comparable within each of these groupings (Important at T10: 7 out of 12; Migrate In: 6 out of 12; Never Important: 14 out of 28 ), although 10 out of 12 of those in the "Migrate In" group were at high risk due to family history.

\subsection{EEG methods}

Resting EEG was measured while participants sat quietly during four 2-min periods (order of eyes-open and eyes-closed counterbalanced across participants) after being instructed to avoid blinking and eye and body movements (fixation cross used for eyes-open condition; e.g., cf. Tenke et al., 2011). Thirteen scalp EEG channels from 10-20 system (Frontal: F7, F3, F4, F8; Central: T7, C3, Cz, C4, T8; Parietal: 
Table 2

Subgroups resulting from prioritizing of R/S importance at assessments T10 and T20.

\begin{tabular}{|c|c|c|c|}
\hline & \multicolumn{2}{|l|}{$\mathrm{T} 20$} & \multirow[t]{2}{*}{ T10 totals } \\
\hline & Important & Not important & \\
\hline \multicolumn{4}{|l|}{$\mathrm{T} 10$} \\
\hline Important & $\begin{array}{l}\text { Always } \\
n=8\end{array}$ & $\begin{array}{l}\text { Migrate Out } \\
n=4\end{array}$ & $\begin{array}{l}\text { Always/Migrate Out } \\
n=12\end{array}$ \\
\hline Not important & $\begin{array}{l}\text { Migrate In } \\
n=12\end{array}$ & $\begin{array}{l}\text { Never } \\
n=28\end{array}$ & $\begin{array}{l}\text { Never/Migrate In } \\
n=40\end{array}$ \\
\hline T20 totals & $\begin{array}{l}\text { Always/Migrate In } \\
n=20\end{array}$ & $\begin{array}{l}\text { Never/Migrate Out } \\
n=32\end{array}$ & $N=52$ \\
\hline
\end{tabular}

Table 3

Characteristics of importance subgroups.

\begin{tabular}{|c|c|c|c|c|c|c|c|}
\hline & \multirow[t]{2}{*}{$n$} & \multicolumn{2}{|c|}{ Family risk of depression } & \multicolumn{2}{|l|}{ Gender } & \multicolumn{2}{|c|}{ Lifetime MDD } \\
\hline & & Low risk & High risk & Female & Male & No MDD & MDD \\
\hline Important at $\mathrm{T} 10$ & 12 & 6 & 6 & 10 & 2 & 5 & 7 \\
\hline Always & 8 & 4 & 4 & 6 & 2 & 3 & 5 \\
\hline Migrate Out & 4 & 2 & 2 & 4 & 0 & 2 & 2 \\
\hline Not important at T10 & 40 & 15 & 25 & 23 & 17 & 20 & 20 \\
\hline Migrate In & 12 & 2 & 10 & 9 & 3 & 6 & 6 \\
\hline \multirow[t]{2}{*}{ Never } & 28 & 13 & 15 & 14 & 14 & 14 & 14 \\
\hline & & 21 & 31 & 33 & 19 & 25 & 27 \\
\hline
\end{tabular}

P7, P3, P4, P8; plus right ear, left ear reference, digitally re-referenced to linkedears; bipolar recordings to monitor for blinks and horizontal eye movements) was measured using an electrode cap (Electro Cap International). The EEG was recorded using a Bioamplifier system (James Long Company) at a gain of $10 \mathrm{~K}$ and a band pass of .01-30 Hz. EEG data were continuously acquired at 200 samples/s (NeuroScan acquire; Neurosoft, 1999) and segmented off-line into consecutive 1.28-s epochs every .64 s (50\% overlap). Epochs contaminated by blinks, eye movements, or movement-related artifacts were excluded using a rejection criterion of $\pm 100 \mu \mathrm{V}$ on any channel, followed by interactive rejection of remaining artifacts (Bruder et al., 2005).

\subsection{Quantification of posterior alpha generators}

EEG recordings are universally affected by the choice of a recording reference, which can be particularly problematic for power spectra (cf. Fig. 1 of Tenke \& Kayser, 2005). In contrast, transforming surface potentials using a surface Laplacian (i.e., CSD), yields reference-independent measures that reflect the underlying neuronal current generators (Tenke \& Kayser, 2012). Artifact-free EEG epochs were transformed to CSD using a spherical spline Laplacian (spline flexibility constant $m=4$, regularization constant $\lambda=10^{-5}, 50$ iterations; Perrin, Pernier, Bertrand, \& Echallier, 1989; Kayser \& Tenke, 2006; cf. Kayser, 2009). The DC offset of each epoch was removed, and the data were tapered over the entire 1.28-s duration using a Hanning window (Bendat \& Piersol, 1971). CSD power spectra were computed, converted to amplitude spectra (Tenke \& Kayser, 2005), and submitted to unrestricted, covariance-based frequency PCA (fPCA) followed by unrestricted Varimax rotation of the covariance loadings (Kayser \& Tenke, 2003). Instead of $\log _{10}$-transformed power spectra (e.g., Pivik et al., 1993), amplitude spectra were used because (1) these EEG spectra can be more easily separated into meaningful spectral components, and (2) a root mean square (RMS) amplitude closely parallels the conceptualization of a temporal component (Tenke \& Kayser, 2005).

\subsection{CSD-fPCA feasibility with 13-channel EEG montage}

The adequacy of 67-channel and 31-channel EEG montages for CSD-fPCA has previously been demonstrated for characterizing and quantifying EEG alpha (Tenke \& Kayser, 2005; Tenke et al., 2011). It has also been shown that a 16-channel montage can be sufficient to identify and quantify posterior alpha differences associated with antidepressant treatment response (supplement S4 of Tenke et al., 2011). However, the present use of a 13-channel montage required additional evaluation for the specific montage. To accomplish this, untransformed EEG epochs from Tenke et al. (2011) were restricted to these 13 channels, subjected to CSD-fPCA analysis, and the solutions compared to those for 67 channels (supplement S1, this paper). Factor loadings waveforms were virtually identical to those from the larger montage, and the original predictions in that study were preserved (albeit with reduced power). It was therefore concluded that CSD-fPCA measures are justified for the montage used in the present study.
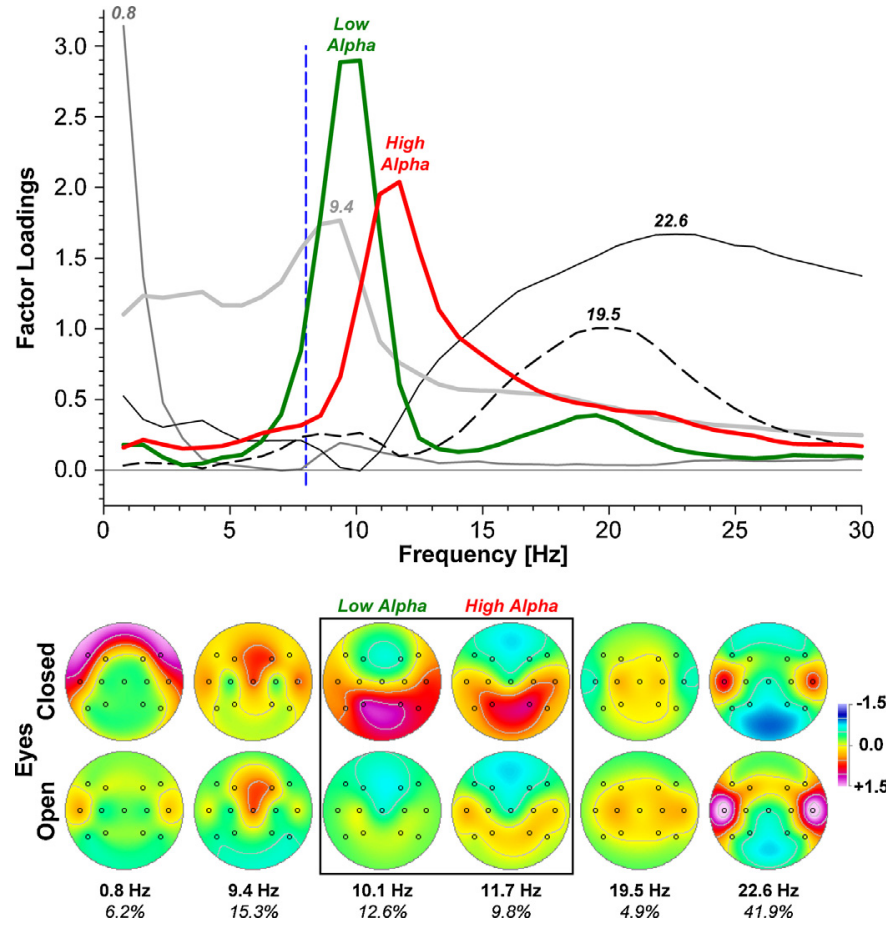

Fig. 1. The first six factors extracted by CSD-fPCA, including factors with low(green) and high-frequency (red) alpha loadings peaks (top), each identified by its peak frequency. Each factor has a characteristic factor score topography and condition dependency (bottom; anterior up; circles identify electrodes). Both alpha factors were greater for eyes-closed than eyes-open, as expected for posterior alpha (Tenke \& Kayser, 2005; Tenke et al., 2011). Factor score labels (below maps) indicate peak frequency of each loadings waveform, with corresponding variance percentages in italics. The PCA solution also included a theta factor (gray; $9.4 \mathrm{~Hz}$ peak) characterized by a midline frontal topography that was unresponsive to condition, discounting it as a contributor to posterior alpha. Vertical dashed blue line in loadings plot indicates nominal $8 \mathrm{~Hz}$ border between theta and alpha bands. Exploratory analyses of theta, as well as ocular $(.8 \mathrm{~Hz})$ and muscle $(22.6 \mathrm{~Hz})$ artifact, suggested no effects of interest. 


\section{A Primary Hypothesis}

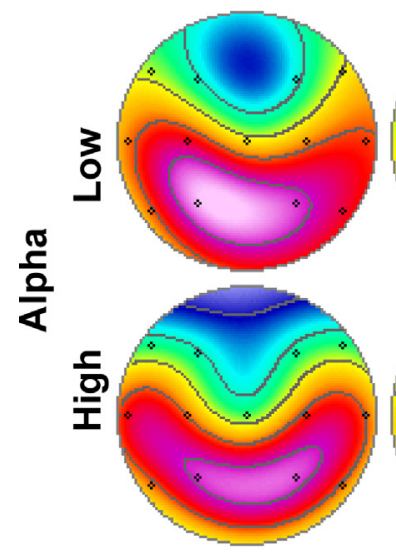

T10 Important $(n=12)$

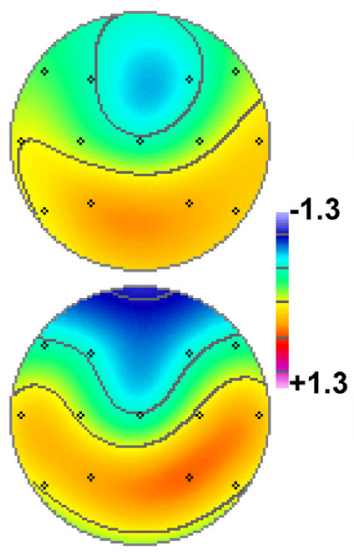

$\mathrm{T} 10$

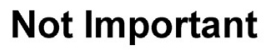

$(n=40)$

\section{B Secondary Hypothesis}

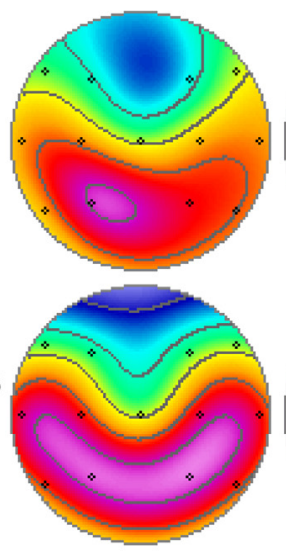

\section{Always \\ $(n=8)$}
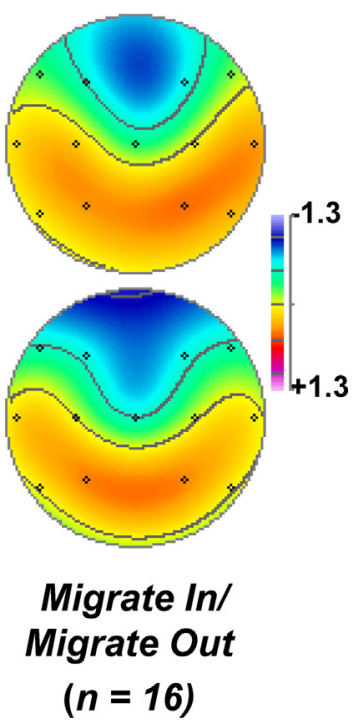

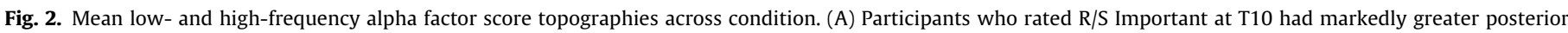

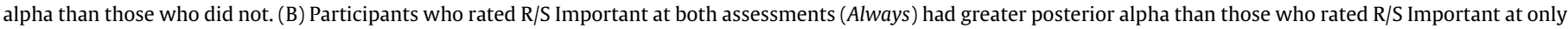
one assessment (Migrate In/Migrate Out).

\subsection{CSD-fPCA solution for present data}

Fig. 1 shows the CSD-fPCA solution characterizing the present data. Low- and high-frequency alpha factors were unambiguously identified by their spectral loadings (top). EEG alpha was quantified using the corresponding factor scores, which conform to the spectral properties of the data, rather than imposing the constraint of a priori, rigidly defined bands (cf. Tenke \& Kayser, 2005). The resulting conditiondependent factor score topographies (bottom) were as expected for posterior alpha (Tenke et al., 2011). All analyses were restricted to these two factors. ${ }^{2}$

\subsection{Statistical methods}

The primary analysis parallels our previous evaluation of depression incidence and relapse over ten years following the assessment of the importance of religion/spirituality at T10 (Miller et al., 2012). Posterior alpha was estimated by high-frequency and low-frequency alpha CSD-fPCA factor scores at medial parietal sites (P3, P4) for each condition (eyes open, eyes closed) and participant ${ }^{3}$. To evaluate our primary hypothesis, alpha was compared for the initial assessment (T10 predictions) using a repeated measures ANOVA with hemisphere (left, right), condition (eyes-open, eyes-closed), and factor (high-frequency alpha, low-frequency alpha) as within-subjects factors, and group (important, not important) as a between-subjects factors (T10 marginals, Table 2 ). ${ }^{4}$

The secondary hypothesis was that those who changed their report of Importance (i.e., Migrate In, Migrate Out) would show less posterior alpha than those who rated R/S as Important at both assessments (i.e., Always), and was evaluated with a comparable ANOVA. Scatterplots of the prominence of posterior alpha for individuals in these groups were used to describe differences between these groups. Individuals were also classified as having prominent- or low-amplitude alpha, following the strategy of Tenke et al. (2011). The resulting contingency tables were

\footnotetext{
2 Midline frontal theta was represented as a distinct factor (Fig. 1, 9.4 Hz). Although an independent anterior midline theta factor is of theoretical importance, in the context of the present study it is sufficient to note that it is distinct from posterior alpha based on the functional (i.e., eyes-open vs. eyes-closed) and topographic characteristics of its factor scores. Moreover, exploratory analyses of theta $(9.4 \mathrm{~Hz})$, ocular $(.8 \mathrm{~Hz})$, and muscle artifact $(22.6 \mathrm{~Hz})$ factors revealed no effects of interest.

3 The within-subjects factors of the repeated measures ANOVA were included to address common concerns in the literature. For example, hemisphere (left, right) addressed the possibility that a posterior alpha amplitude effect might be observed over one hemisphere, but not when pooled across both hemispheres (i.e., it may be asymmetric).

${ }^{4}$ Significant Group main effects were also verified using a Mann-Whitney $U$. Although gender was not used as an ANOVA factor, significant findings were verified using an ANOVA restricted to female participants.
}

then subjected to follow-up tests (Fisher exact test) to describe the observed correspondence between EEG alpha and lifetime MDD.

\section{Results}

As predicted by the primary hypothesis, the 12 participants who rated R/S Important at T10 showed significantly greater medialposterior CSD alpha $(M \pm S D, 1.12 \pm .59)$ when compared to 40 who rated $\mathrm{R} / \mathrm{S}$ Not Important $(0.33 \pm 0.63, F[1,50]=15.18, p<.001)$. This group difference in alpha was evident for both low- and highfrequency alpha factors (cf. Fig. 2A). As expected, alpha was greater for eyes closed compared to eyes open $(F[1,50]=70.1, p<.001)$ These main effects were supplemented by a marginally significant group $\mathrm{x}$ condition interaction $(F[1,50]=3.40 ; p=.07)$ stemming from greater condition-related differences for those who rated $\mathrm{R} / \mathrm{S}$ as important (closed: $1.74 \pm 0.91$; open: $.51 \pm 0.51$ ) compared to those who did not (closed: $.72 \pm 0.93$; open: $-.07 \pm 0.42$ ). There were no other significant effects. The secondary prediction, that greater alpha would be observed in participants who consistently rated R/S as Important at T10 and T20 when compared to those who changed their ratings (Fig. 2B), was supported by a significant group main effect (Always [ $n=8]: 1.00 \pm 0.65$; Migrate Out/Migrate In $[n=16]: .39 \pm 0.71 ; F[1,22]=4.21, p=.05)$.

Fig. 3 illustrates the scatterplots of the alpha factor scores for each individual in the Importance groupings used to test the primary hypothesis: "Important at T10" (Always/Migrate out) and "Not Important at T10" (Migrate In/Never). Although the difference between these groups is clear, it is also apparent that the difference identified by the secondary hypothesis (greater alpha for Always compared to Migrate Out/Migrate In) stems from the incidence of low-amplitude alpha specific to the Migrate In group. However, the alpha factor score for Never group had a very wide range, overlapping all but one individual who rated $\mathrm{R} / \mathrm{S}$ as important at either time, and a median (dashed line) that provided a useful classification of individuals in the "Important" groupings (i.e., Always, Migrate Out and Migrate $I n$ ) based on alpha amplitude. Most individuals who identified religion as Important at T10 (Always/Migrate Out) had greater alpha (11 out of 12 ), whereas most of those who identified R/S as Important only at T20 (Migrate In) had less alpha 


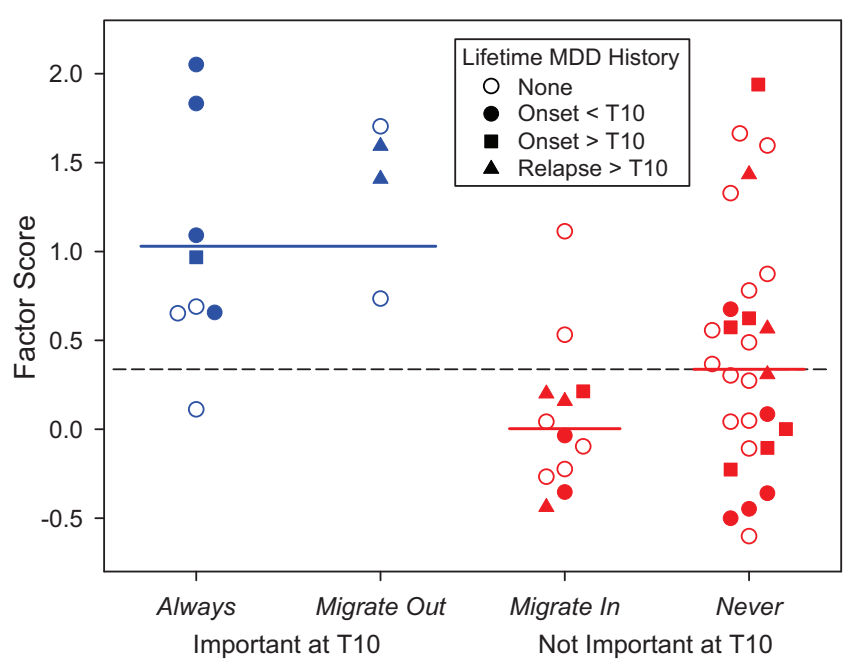

Fig. 3. Scatterplot of factor score means of medial posterior CSD alpha (averaged across factors, conditions and hemispheres) for individuals in each of the Importance groups. As hypothesized, Alpha was greater for "Important at T10" than for "Not Important at T10." The secondary prediction, of greater alpha for Always Important than for Migrate Out/Migrate In, is also evident. The Migrate In group had less alpha than the Always Important group, but the Migrate Out did not (medians for Always/Migrate out, Migrate In and Never are shown as solid lines). The median for Never Important (dashed line), was used to distinguish between prominent alpha and low-amplitude alpha. Group differences were enhanced for participants with a personal history of depression (filled symbols), showing no overlap between Always/Migrate Out and Migrate In groups.

(10 out of 12; Fisher exact test of association, $p=.001$ ). These differences were likewise observed separately for eyes-closed and eyes-open.

A complete description of the impact of time on ratings of $\mathrm{R} / \mathrm{S}$ will require a substantially larger sample (cf. Tables 2 and 3). However, we note that the four Migrate Out participants showed as prominent alpha as the Always group. Differences between Always/Migrate Out and Migrate In groups were also seen for subsamples having either a lifetime history of MDD (Fisher's exact $p=.002$; cf. filled symbols in Fig. 3 ) or who were at risk due to a family history of depression (Fisher's exact $p=.007$; not shown), but not for those who had no lifetime MDD ( $p>.1$; cf. open symbols in Fig. 3). Interestingly, two of the four Migrate Out participants had a history of MDD, and they both experienced a subsequent recurrence of MDD by the second assessment, despite showing prominent EEG alpha (Fig. 3, filled triangles). Also, only one of the Always Important group experienced a MDD after the first assessment, and none of them relapsed between the two assessments.

\section{Discussion}

Self-reports of the personal importance of religion or spirituality have been shown to be predictive of a reduced risk of depression, notably recurrence in adults with a family history of depression (Miller et al., 2012). As hypothesized, those individuals who selfreport a high personal importance of $\mathrm{R} / \mathrm{S}$ had significantly greater posterior resting EEG alpha when measured at the end of the ten year evaluation period. In accord with our secondary hypothesis, those whose self-report of the importance of R/S changed between evaluations had less alpha than those who retained a high importance of R/S. Surprisingly, those who expressed importance of R/S only at T20 (Migrate In) showed low-amplitude alpha. These differences were not a result of differences in MDD history between groups. To the contrary, they were particularly well-defined for comparisons restricted to individuals with a lifetime history of depression (i.e., no overlap for Always/Migrate out and Migrate In; Fig. 3).
In view of the wealth of evidence for an influence of religious or spiritual beliefs as protective against depression, substance use and abuse and a broad range of physical illnesses (for reviews see Koenig, King, \& Carson, 2012; Park \& Slattery, 2012; Plante \& Thoresen, 2012), as well as a source of resilience and positive psychology assets cross-denominationally and cross-nationally (Benson, Roehlkepartain, \& Scales, 2012; Ciarrocchi, 2012) and as contributing overall toward improved treatments for psychopathology (Rosmarin et al., 2013), the sparsity of papers dealing with spirituality in mainstream scientific literature is problematical. Acknowledging the absence of a practical, comprehensive approach to these issues in the literature, Peteet (2012) suggested a conceptual framework for dealing with the relationship between depression, spirituality, and mental health treatment. However, the specificity of the protection imparted by $R / S$ is by no means established. The protective role of $\mathrm{R} / \mathrm{S}$ presumably acts through neurobiological processes shared with other, better studied indices of depression risk and outcome. For example, religious affiliations and practices provide access to multiple mechanisms known to be protective against anxiety and depression, including social support networks, informal group and individual counseling, an environment intended to foster purposiveness and hope (e.g., Oetting, Deffenbacher, \& Donnermeyer, 1998a, 1998b), as well as the personal practice of meditation and/or prayer. Not surprisingly, mindfulness-based cognitive therapy may offer a similar protection against depression (e.g., Young, 2011). However, the risk for MDD was not improved by attendance at church services, or for particular religious denominations (Miller et al., 2012; although see Balbuena, Baetz, \& Bowen, 2013), indicating that these formal attributes may not be important for the observed protective effect.

One fundamental concern about the Importance classifications is the consistency with which the expression "religion or spirituality" might have been interpreted. Previous research has shown that personal importance of R/S correlates highly (.7) with the well validated Fetzer scales of daily spiritual experience and transcendence, and only moderately with measures of religious practice and belief (Kelley \& Miller, 2007), suggesting that the item is interpreted to reflect an inner experience of $\mathrm{R} / \mathrm{S}$. This single item is the most widely used measure of R/S in health research (Larson \& Larson, 1994), has been associated with a wide range of positive health outcomes, and has been shown to have strong predictive validity. The general presence or absence of personal experience of $\mathrm{R} / \mathrm{S}$ may carry more relevance to health than the more fine grain measures of practice, beliefs or denomination (Koenig et al., 2001). Moreover, personal R/S has been shown to reflect a protective factor that shares a biological basis with both familial risk for depression and recovery from depression (Jacobs et al., 2012; Miller et al., 2012, 2013). One may therefore propose that personal R/S is intimately, if not fundamentally, related to affective function.

To the extent that meditation or prayer share a physiological basis in the mechanisms of relaxation, a prominent posterior alpha rhythm might be expected to counter depression risk on a functional basis as a form of stress-reduction. By the same reasoning, a propensity of high-amplitude alpha individuals for spiritual practices might parallel those of physical stamina or coordination for athletics or dance. However, the present findings are not consistent with a disappearance of the EEG correlates of Importance (i.e., increased alpha) with disuse. The few Migrate Out cases exhibited high-amplitude alpha, even following a recurrence of MDD symptomatology. This suggests that the prominent posterior alpha may be a marker for responsivity to an implicit behavioral intervention (spiritual practice), regardless of whether the individual requires it at the time or chooses to use it.

In studies of depression, prominent alpha has been associated with better outcomes of treatment with antidepressants (Bruder et al., 2008; Tenke et al., 2011; Ulrich, Renfordt, \& Frick, 1986). 
It is not yet clear to what extent differences in EEG alpha reflect responsivity to antidepressant treatments that is distinct from an underlying general vulnerability to depression or propensity toward recovery. Our separate identification of an association between posterior, condition-dependent alpha and a family history of MDD (Bruder et al., 2005) and responsiveness to antidepressants (Tenke et al., 2011) suggest that prominent EEG alpha may serve as a marker for a cluster of related biological, affective and hedonic predispositions. The same predisposition that presents itself as a vulnerability to MDD may also foretell a positive outcome following treatment with antidepressants, as well as a propensity toward religious or spiritual practice. In this regard, some of those identifying as Never Important may simply be unclassifiable by this metric, having a "spiritual" appreciation of the natural world or human society, but a reluctance to equate them with religious practices.

The CSD-fPCA measures identified in this study unambiguously represent the posterior neuronal generators that underlie EEG alpha, as well as the condition-related differences that characterize classic posterior alpha (Tenke \& Kayser, 2005; Tenke et al., 2011; Tenke \& Kayser, 2012). However, the differences in alpha attributable to Importance were observed both for eyes-open and eyes-closed conditions. It must also be recognized that the design of the present study cannot distinguish between persistent EEG patterns or endophenotypes of relevance to depression and changes in these patterns that may impart a resistance to depression, nor is it clear whether or not the observed physiological or behavioral differences will persist. Because of these issues, caution must be exercised when drawing parallels between the present results with those obtained for predictors of treatment response. Finally, the theoretical and practical advantages of reference-independent CSD methodology enhance the physiological interpretability of the data, but do not assure comparability with results based on conventional, reference-dependent EEG measures. However, it must be recognized that traditional EEG measures will differ among themselves, depending on the recording reference scheme that is used.

The appearance and persistence of $\mathrm{R} / \mathrm{S}$ practices across cultures and over millenia strongly suggest that they have a functional significance, whether for the individual practitioner or for the culture in which they take place. It must be emphasized that the present study in no way characterizes spirituality per se, but merely physiological characteristics of those who rate it as important. The association between spirituality and depression is likewise descriptive, and is at present more useful for describing groups of individuals than for evaluating the functional and causal processes at work. Because of the nature of the R/S measure, we do not have sufficient information about the reasons particular individuals may have had for changing their R/S Importance ratings between assessments. Either increases or decreases might be expected to be associated with life challenges and crises. Notably, those in the Migrate In group were disproportionately at high risk due to family history, rendering any statements about low-risk Migrate In participants purely speculative. It is also unclear whether the unique, ongoing cooperation of the participants in this multigenerational study might itself influence measures that are commonly associated with the maintenance of traditions across generations. Although a larger sample of males is sorely needed, the effects reported here also hold for females only. Finally, additional data are needed to distinguish the contributions of state, trait and adjustment strategy to the observed differences.

\section{Disclosures}

Drs. Tenke, Kayser, Warner, Wickramaratne and Bruder have no disclosures to make. Dr. Miller has received funding from the Templeton Foundation, the Klingenstein Fund, and the Pritchard
Foundation, and received payment from Oxford University Press. Dr. Weissman has received funding from NIMH, the National Institute on Drug Abuse (NIDA), NARSAD, the Sackler Foundation, the Templeton Foundation, and the Interstitial Cystitis Association, and receives royalties from Oxford University Press, Perseus Books, American Psychiatric Association Press, and MultiHealth Systems.

\section{Acknowledgments}

Supported by the John Templeton Foundation. The data collection was funded by NIMH grant MH36197, which includes a supplement from NIDA. Development of CSD methods was funded by MH36295. The authors would also like to thank Christian Grillon, in whose lab the EEG data were recorded. Finally, we appreciate the suggestions of the Associate Editor, Frances Martin, and two anonymous reviewers, which greatly improved this paper.

\section{Appendix A. Supplementary data}

Supplementary data associated with this article can be found, in the online version, at http://dx.doi.org/10.1016/j.biopsycho.2013. 08.001 .

\section{References}

Allen, J. J. B., \& Cohen, M. X. (2010). Deconstructing the "resting" state: Exploring the temporal dynamics of frontal alpha asymmetry as an endophenotype for depression. Frontiers in Human Neuroscience, 4, 232-245.

Balbuena, L., Baetz, M., \& Bowen, R. (2013). Religious attendance, spirituality, and major depression in Canada: A 14-year follow-up study. Canadian Journal of Psychiatry, 58, 225-232.

Bendat, J. S., \& Piersol, A. G. (1971). Random data: Analysis and measurement procedures. New York, NY: Wiley-Interscience.

Benson, P. L., Roehlkepartain, G., \& Scales, P. C. (2012). Spirituality and positive youth development. In L. Miller (Ed.), Oxford University Press handbook of psychology and spirituality (pp. 379-387). New York: Oxford University Press.

Bruder, G. E., Fong, R., Tenke, C. E., Leite, P., Towey, J. P., Stewart, J. E., et al. (1997). Regional brain asymmetries in major depression with or without an anxiety disorder: A quantitative EEG study. Biological Psychiatry, 41, 939-948.

Bruder, G. E., Tenke, C. E., Warner, V., Nomura, Y., Grillon, C., Hille, J., et al. (2005). Electroencephalographic measures of regional hemispheric activity in offspring at risk for depressive disorders. Biological Psychiatry, 57, 328-335.

Bruder, G. E., Sedoruk, J. P., Stewart, J. W., McGrath, P. J., Quitkin, F. M., \& Tenke, C. E. (2008). Electroencephalographic alpha measures predict therapeutic response to a selective serotonin reuptake inhibitor antidepressant: Pre- and posttreatment findings. Biological Psychiatry, 63, 1171-1177.

Bruder, G. E., Bansal, R., Tenke, C. E., Liu, J., Hao, X., Warner, V., et al. (2012). Relationship of resting EEG with anatomical MRI measures in individuals at high and low risk for depression. Human Brain Mapping, 33, 1325-1333.

Cahn, B. R., \& Polich, J. (2006). Meditation states and traits: EEG, ERP, and neuroimaging studies. Psychological Bulletin, 132, 180-211.

Ciarrocchi, J. W. (2012). Positive psychology and spirituality: A virtue approach to well being. In L. Miller (Ed.), Oxford University Press handbook of psychology and spirituality (pp. 425-436). New York: Oxford University Press.

Davidson, R. J. (1992). Anterior cerebral asymmetry and the nature of emotion. Brain and Cognition, 20, 125-151.

Gloor, P. (1969). Hans Berger and the discovery of the electroencephalogram. Electroencephalography and Clinical Neurophysiology Supplement, 28, 1-36.

Henriques, J. B., \& Davidson, R. J. (1990). Regional brain electrical asymmetries discriminate between previously depressed and healthy control subjects. Journal of Abnormal Psychology, 99, 22-31.

Idler, E. L., Musick, M. A., Ellison, C. G., George, L. K., Krause, N., Ory, M. G., et al. (2003). Measuring multiple dimensions of religion and spirituality for health research: Conceptual background and findings from the 1998 General Social Survey. Research on Aging, 25, 327-365.

Jacobs, M., Miller, L., Wickramaratne, P., Gameroff, M., \& Weissman, M. M. (2012). Family religion and psychopathology in children of depressed mothers: Tenyear follow-up. Journal of Affective Disorders, 136, 320-327.

Kayser, J. (2009). Current source density (CSD) interpolation using spherical splines: CSD toolbox. Available at http://psychophysiology.cpmc. columbia.edu/Software/CSDtoolbox

Kayser, J., Bruder, G. E., Tenke, C. E., Stewart, J. W., \& Quitkin, F. M. (2000) Event-related potentials (ERPs) to hemifield presentations of emotional stimuli: Differences between depressed patients and healthy adults in P3 amplitude and asymmetry. International Journal of Psychophysiology, 36, 211-236.

Kayser, J., \& Tenke, C. E. (2003). Optimizing PCA methodology for ERP component identification and measurement: Theoretical rationale and empirical evaluation. Clinical Neurophysiology, 114, 2307-2325. 
Kayser, J., \& Tenke, C. E. (2006). Principal components analysis of Laplacian waveforms as a generic method for identifying ERP generator patterns: I. Evaluation with auditory oddball tasks. Clinical Neurophysiology, 117, 348-368.

Kelley, B., \& Miller, L. (2007). Life satisfaction and spirituality in adolescents. Research in the Social Scientific Study of Religion, 18, 233-261.

Kendler, K. S., Gardner, C. O., \& Prescott, C. A. (1997). Religion, psychopathology, and substance use and abuse; a multimeasure, genetic-epidemiologic study. American Journal of Psychiatry, 154, 322-329.

Knott, V. J., Telner, J. I., Lapierre, Y. D., Browne, M., \& Horn, E. R. (1996). Quantitative EEG in the prediction of antidepressant response to imipramine. Journal of Affective Disorders, 39, 175-184.

Koenig, H. G., McCullough, M. E., \& Larson, D. B. (2001). Handbook of religion and health. New York: Oxford University Press.

Koenig, H., King, D. A., \& Carson, V. B. (2012). Oxford University Press handbook of religion and health. New York: Oxford University Press.

Korb, A. S., Hunter, A. M., Cook, I. A., \& Leuchter, A. F. (2009). Rostral anterior cingulate cortex theta current density and response to antidepressants and placebo in major depression. Clinical Neurophysiology, 120, 1313-1319.

Larson, D. B., \& Larson, S. (1994). The forgotten factor in physical and mental health: What does the research show? Rockville, MD: National Institute for Healthcare Research.

Larson, D. B., \& Larson, S. S. (2003). Spirituality's potential relevance to physical and emotional health: A brief review of quantitative research. Journal of Psychology and Theology, 31, 37-51

Miller, L., Warner, V., Wickramaratne, P., \& Weissman, M. (1997). Religiosity and depression: Ten-year follow-up of depressed mothers and offspring. Journal of the American Academy of Child and Adolescent Psychiatry, 36, 1416-1425.

Miller, L., Wickramaratne, P., Gameroff, M. J., Sage, M., Tenke, C. E., \& Weissman, M. M. (2012). Religiosity and major depression in adults at high risk: A ten-year prospective study. American Journal of Psychiatry, 169, 89-94.

Miller, L., Bansal, R., Wickramaratne, P., Xoa, X., Tenke, C. E., Weissman, M. M., \& Peterson, B. S. (2013). Neuroanatomical correlates of religiosity and spirituality in adults at high and low familial risk for depression. JAMA Psychiatry (in press).

Mulert, C., Juckel, G., Brunnmeier, M., Karch, S., Leicht, G., Mergl, R., et al. (2007). Prediction of treatment response in major depression: Integration of concepts. Journal of Affective Disorders, 98, 215-225.

Neurosoft, Inc. (1999). SCAN 4.1 - Vol. I. Acquire 4.1 - Online acquisition of neurophysiological data (Document number 2202, Revision A). Sterling, Virginia: Neuroscan.

Nunez, P. L., \& Srinivasan, R. (2006). Electric fields of the Brain: The neurophysics of EEG (2nd ed.). New York: Oxford University Press.

Oetting, E. R., Deffenbacher, J. L., \& Donnermeyer, J. F. (1998). Primary socialization theory. The role played by personal traits in the etiology of drug use and deviance. II. Substance Use and Misuse, 33, 1337-1366.

Oetting, E. R., Donnermeyer, J. F., \& Deffenbacher, J. L. (1998). Primary socialization theory. The influence of the community on drug use and deviance. III. Substance Use and Misuse, 33, 1629-1665.

Park, C., \& Slattery, J. M. (2012). Spirituality, emotions and physical health. In L. Miller (Ed.), Oxford University Press handbook of psychology and spirituality (pp. 379-387). New York: Oxford University Press.

Perrin, F., Pernier, J., Bertrand, O., \& Echallier, J. F. (1989). Spherical splines for scalp potential and current density mapping. Electroencephalography and Clinical Neurophysiology, 72, 184-187 [Corrigenda EEG 02274, EEG clin Neurophysiol 1990, $76,565]$.

Peteet, J. R. (2012). Spiritually integrated treatment of depression: A conceptual framework. Depression Research and Treatment, 2012, 124370.

Peterson, B. S., Warner, V., Bansal, R., Zhu, H., Hao, X., Liu, J., et al. (2009). Cortical thinning in persons at increased familial risk for major depression. Proceedings of the National Academy of Sciences of the United States of America, 106, 6273-6278.

Pivik, R. T., Broughton, R. J., Coppola, R., Davidson, R. J., Fox, N., \& Nuwer, M. R. (1993). Guidelines for the recording and quantitative analysis of electroencephalographic activity in research contexts. Psychophysiology, 30, 547-558.
Pizzagalli, D., Pascual-Marqui, R. D., Nitschke, J. B., Oakes, T. R., Larson, C. L Abercrombie, H. C., et al. (2001). Anterior cingulate activity as a predictor of degree of treatment response in major depression: Evidence from brain electrical tomography analysis. American Journal of Psychiatry, 158, 405-415.

Plante, T., \& Thoresen, C.E.(2012). Spirituality, religion and psychological counseling. In L. Miller (Ed.), Oxford University Press handbook of psychology and spirituality (pp. 388-409). New York: Oxford University Press.

Pollock, V. E., \& Schneider, L. S. (1989). Topographic electroencephalographic alpha in recovered depressed elderly. Journal of Abnormal Psychology, 98, 268-273.

Pollock, V. E., \& Schneider, L. S. (1990). Topographic quantitative EEC in elderly subjects with major depression. Psychophysiology, 27 438-444.

Rosmarin, D. H., Bigda-Peyton, J. S., Kertz, S. J., Smith, N., Rauch, S. L., \& Björgvinsson, T. (2013). A test of faith in God and treatment: The relationship of belief in God to psychiatric treatment outcomes. Journal of Affective Disorders, 146, 441-446.

Smith, T. B., McCullough, M. E., \& Poll, J. (2003). Religiousness and depression: Evi dence for a main effect and the moderating influence of stressful life events. Psychological Bulletin, 129, 614-636.

Stewart, J. L., Towers, D. N., Coan, J. A., \& Allen, J. J. B. (2011). The oft-neglected role of parietal EEG asymmetry and risk for major depressive disorder. Psychophysiology, 48, 82-95.

Tenke, C. E., \& Kayser, J. (2005). Reference-free quantification of EEG spectra: Combining current source density (CSD) and frequency principal components analysis (fPCA). Clinical Neurophysiology, 116, 2826-2846.

Tenke, C. E., \& Kayser, J. (2012). Generator localization by current source density (CSD): Implications of volume conduction and field closure at intracranial and scalp resolutions. Clinical Neurophysiology, 123, 2328-2345.

Tenke, C. E., Kayser, J., Stewart, J. W., \& Bruder, G. E. (2010). Novelty P3 reductions in depression: Characterization using principal components analysis (PCA) of current source density (CSD) waveforms. Psychophysiology, 47, 133-146.

Tenke, C. E., Kayser, J., Manna, C. B. G., Fekri, S., Kroppmann, C. J., Schaller, J. D., et al. (2011). Current source density measures of EEG alpha predict antidepressant treatment response. Biological Psychiatry, 70, 388-394.

Tenke, C. E., Kayser, J., Alvarenga, J., Abraham, K., Alschuler, D. M., \& Bruder, G. E. (2013). Antidepressant treatment response: Association between current source density (CSD) spectral measures obtained at rest and during novelty oddball performance, Program No. 540.13.2013. In Neuroscience Meeting Planner. San Diego, CA: Society for Neuroscience. Online.

Tsuang, M. T., Williams, W. M., Simpson, J. C., \& Lyons, M. J. (2002). Pilot study of spirituality and mental health in twins. American Journal of Psychiatry, 159, 486-488.

Ulrich, G., Renfordt, E., \& Frick, K. (1986). The topographical distribution of alpha-activity in the resting EEG of endogenous-depressive inpatients with and without clinical-response to pharmacotherapy. Pharmacopsychiatry, 19 , $272-273$.

Ulrich, G., Haug, H. J., Stieglitz, R. D., \& Fähndrich, E. (1988). EEG characteristics of clinically defined on-drug-responders and non-responders-A comparison clomipramine vs. maprotiline. Pharmacopsychiatry, 21, 367-368.

Weissman, M. M., Warner, V., Wickramaratne, P., Moreau, D., \& Olfson, M. (1997) Offspring of depressed parents: Ten years later. Archives of General Psychiatry, 54, 932-940.

Weissman, M. M., Wickramaratne, P., Nomura, Y., Warner, V., Verdeli, H., Pilowsky D. J., et al. (2005). Families at high and low risk for depression: A 3-generation study. Archives of General Psychiatry, 62, 29-36.

Weissman, M. M., Wickramaratne, P., Nomura, Y., Warner, V., Pilowsky, D., \& Verdeli, H. (2006). Offspring of depressed parents: 20 years later. American Journal of Psychiatry, 163, 1001-1008.

Young. S. N. (2011). Biologic effects of mindfulness meditation: Growing insights into neurobiologic aspects of the prevention of depression. Journal of Psychiatry and Neuroscience, 36, 75-77. 